\title{
Pelatihan Perawatan Payudara dengan Media Phantom Sebagai Treatment Keberhasilan ASI Ekslusif
}

\author{
Rahmah Hida Nurrizka*1, Dwi Mutia Wenny² \\ ${ }^{1}$ Department of Public Health, Faculty of Health Science, Universitas Islam Negeri Syarif Hidayatullah \\ Jakarta \\ ${ }^{2}$ Department of Public Health, Faculty of Health Science, Universitas Pembangunan Nasional Veteran \\ Jakarta \\ *e-mail: rh.nurrizka@uinjkt.ac.id ${ }^{1}$, dwimutiawenny@gmail.com²
}

\begin{abstract}
One of the goals of the SDGs (Sustainable Development Goals) program is to end all forms of malnutrition with a strategic plan (strategic plan) to increase the percentage of babies less than 6 months who receive exclusive breastfeeding. Many mothers complain that their babies do not want to breastfeed. Usually, this is caused by technical factors such as the incoming nipple or the wrong nursing position. For this reason, efforts to educate pregnant women regarding exclusive breastfeeding are very important, followed by providing breast care training with Phantom Media. In increasing breastfeeding to infants, mothers need help and information and support to care for the breast during pregnancy to prepare for breastfeeding. From the results of the service, it can be seen that there are differences in the knowledge of pregnant women before and after being given education-related to exclusive breastfeeding and breast care with sig. (2-tailed) of $0.0<0.05$. From these results, it can be concluded health education can provide pregnant women with more healthrelated knowledge.
\end{abstract}

Keywords: Knowledge, exclusive breastfeeding, breast care, phantom.

\begin{abstract}
Abstrak
Salah satu goal dari program SDGs (Sustainable Development Goals) adalah mengakhiri segala bentuk malnutrisi dengan rencana strategi (renstra) meningkatkan presentase bayi kurang dari 6 bulan yang mendapatkan ASI eksklusif. Banyak ibu yang mengeluh bayinya tidak mau menyusu, biasanya ini disebabkan oleh faktor teknis seperti puting susu yang masuk atau posisi menyusui yang salah. Untuk itu upaya memberikan edukasi kepada ibu hamil terkait ASI Ekslusif sangat penting, diikuti dengan memberikan pelatihan perawatan payudara dengan Media Phantom. Metode pelatihan adalah tutorial, diskusi dan praktek. Peserta pelatihan sebagnyak 25 orang. Dalam meningkatkan pemberian ASI pada bayi, ibu-ibu membutuhkan bantuan dan informasi serta dukungan agar merawat payudara pada saat hamil untuk mempersiapkan pemberian ASI. Jenis media yang baik merupakan salah satu kunci bagi keberhasilan pemberian edukasi.
\end{abstract}

Kata Kunci: Perawatan payudara, media phantom, ASI ekslusif.

\section{PENDAHULUAN}

Balita yang tidak mendapatkan ASI Ekslusif akan berisiko mengalami masalah gizi (Pengan et al., 2015). Masalah gizi yang tidak ditangani dengan baik lebih lanjut akan mengakibatkan kejadian stunting. Berdasarkan data dari Dinas kesehatan provinsi Banten, prevalensi kejadian stunting di Provinsi Banten yaitu sebesar 27\%, kab/kota yang terbesar yaitu Kota Serang sebesar 39,3 \% dan terendah yaitu Kota Tangerang selatan sebesar 11,6 \%.

Salah satu goal dari program SDG's (Sustainable Development Goals) adalah mengakhiri segala bentuk malnutrisi dengan rencana strategi (renstra) meningkatkan presentase bayi kurang dari 6 bulan yang mendapatkan ASI eksklusif (SDG's Ditjen BGKIA, 2015). Untuk itu perlu dipersiapkan agar setiap bayi yang lahir dapat mendapatkan ASI yang cukup yang tidak terhalang karnna putting yang datar atau kegagalan menyusui lainnya.

Cakupan ASI eksklusif di daerah Banten lebih rendah dari jawa Barat dan DKI Jakarta (Kemenkes, 2018). Manajemen laktASI dilakukan guna mendukung keberhasilan menyusui, pada masa kehamilan salah satu manajemen yang harus dilakukan ibu hamil adalah perawatan 
payudara sejak kehamilan 6 bulan hingga ibu siap untuk menyusui sehingga ibu mampu memproduksi dan memberikan ASI yang mencukupi kebutuhan bayi (Jafar, 2011).

Prevalensi pemberian ASI Ekslusif di Provinsi BAnten masih rendah dibandingkan dengan persentase nasional yaitu hanya berkisar 40,42\% (Pusdatin, 2018). Data tersebut memperlihatkan perlunya perhatian yang lebih terhadap pemberian ASI pada bayi mengingat banyak dampak positif dari ASI. Manfaat dari ASI tersebut antara lain, dapat menurunkan morbiditas dan mortalitas bayi, mengoptimalkan pertumbuhan bayi, meningkatkan kecerdasan anak, dan membantu memperpanjang jarak kehamilan bagi ibu (Kemenkes, 2017).

Namun, banyak faktor yang mempengaruhi seseorang ibu dalam memberika ASI pada bayinya antara lain yaitu pengetahuan ibu terkait ASI dan bendungan ASI (Alam and Syahrir, 2016). Permasalahan tersebut diakibatkan ibu hamil tidak menyadari pentingnya perawatan payudara dan pentingnya pemberian ASI Ekslusif pada bayinya. Dengan pemberian edukasi dan pelatihan pada ibu hamil dapat memberikan pengetahuan dan keterampilan terkait peraawatan payudara dan ASI eskslusif. Pengetahuan ibu juga memberikan hubungan terhadap pemberian ASI Ekslusif, beberapa penelitian memperlihatkan terdapat hubungan yang signifikan antara pengetahuan ibu terhadap pemberian ASI Ekslusif (Fahriani, Rohsiswatmo and Hendarto, 2014).

Sebagian besar wanita dalam masyarakat dunia ketiga menyusui bayinya tanpa mempersiapkan payudaranya terlebih dahulu. (Farrer, 2001). Perawatan payudara (breast care) adalah suatu cara merawat payudara yang dilakukan pada saat kehamilan atau masa nifas untuk produksi ASI, selain itu untuk kebersihan payudara dan bentuk puting susu yang masuk ke dalam atau datar. Disamping itu juga sangat penting memperhatikan kebersihan personal hygiene (Rustam, 2009).

Perawatan payudara (Breast Care) adalah suatu cara merawat payudara yang dilakukan pada saat kehamilan atau masa nifas untuk produksi ASI, selain itu untuk kebersihan payudara dan bentuk puting susu yang masuk ke dalam atau datar. Puting susu demikian sebenarnya bukanlah halangan bagi ibu untuk menyusui dengan baik dengan mengetahui sejak awal, ibu mempunyai waktu untuk mengusahakan agar puting susu lebih mudah sewaktu menyusui. Disamping itu juga sangat penting memperhatikan kebersihan personal hygiene (Rustam,2009).

Perawatan payudara merupakan salah satu upaya dalam membantu ibu untuk dapat memberikan ASI secara ekslusif kerena ibu yang melakukan perawatan payudara mencegah terjadinya bendungan ASI saat menyusui, beberapa penelitian memperlihatkan bahwa ada hubungan antara perawatan payudara dengan kejadian bendungan ASI (Meihartati, 2017).

Ibu yang tidak menyusui bayinya, antara lain bisa dikarenakan air susu tidak keluar dan akhirnya mengakibatkan pembekakan payudara atau bendungan ASI. Bendungan ASI (Engorgement) itu dikarenakan penyempitan pada duktus laktiferus, sehingga sisa ASI terkumpul pada system duktus yang mengakibatkan terjadinya pembekakan, penyababnya dikarenakan adanya kelainan pada puting susu, payudara bengkak, nyeri, dan panas (Anggraini, 2010).

Dengan perawatan payudara yang dilakukan, akan memberikan manfaat antara lain: melancarkan refleks pengeluaran ASI atau refleks letdown, meningkatkan volume ASI dan mencegah bendungan pada payudara yang bisa menyebabkan payudara bengkak. Puting susu tidak boleh disentuh dengan tangan yang belum dicuci bersih dan saputangan tidak boleh digunakan sebagai ganjal dibalik BH untuk menghentikan perembesan ASI. Bantalan disposable kini sudah tersedia untuk keperluan ini dan dapat dikenakan dalam waktu relative singkat jika perembesan ASI menimbulkan masalah. Ibu harus menggunakan pakaian yang tidak menghalangi pemberian ASI.

Selama kehamilan, papila harus disiapkan agar menjadi lentur, kuat dan tidak ada sumbatan. Persiapan dilakukan setiap hari sebanyak dua kali sehari setelah usia kehamilan tujuh bulan. Caranya dengan kompres masingmasing putting susu selama dua sampai tiga menit dengan kapas yang dibasahi minyak, kemudian tarik dan putar putting ke arah luar 20 kali, ke arah dalam 
20 kali. Pijat daerah areola untuk membuka saluran susu. Bila keluar cairan, oleskan ke papila dan sekitarnya. Kemudian payudara dibersihkan dengan handuk yang lembut. Putting susu yang terbenam atau datar perlu dikoreksi agar dapat menonjol keluar sehingga siap untuk disusukan kepada bayi. Masalah ini dapat diatASI dengan bantuan pompa putting ("nipple puller") pada minggu terakhir kehamilan.

\section{METODE}

Pelatihan perawatan payudara ini dilakukan secara offline selama 1 hari bertempat di Puskesmas Pondok Cabe Ilir. Populasi dalam penelitian ini adalah Ibu Hamil yang ada di wilayah kerja Puskesmas Pondok Cabe Ilir Provinsi Banten sebanyak 25 orang. Media yang digunakan yaitu phantom dan power point. Terdapat metode yang digunakan dalam pemberian pelatihan perawatan payudara yaitu: 1) Metode sosialisasi: dimana pada metode ini diberikan paparan yang menggambarkan cara perawatan payudara pada ibu hamil. 2) Metode tutorial dan praktik: narasumber memutarkan beberapa video yang memuat cara perawatan payudara serta melakukan praktik secara langsung pada phantom payudara yang sudah disediakan. 3) metode diskusi: narsumber melakukan tanya jawab kepada peserta pelatihan serta beberapa peserta melakukan secara langsung praktek dengan menggunakan phantom. 4) metode evaluasi: dimana peserta diberikan sebuah kuesioner yang berisikan pertanyaan terkai dengan pengetahuan terkai perawatan payudara

\section{HASIL DAN PEMBAHASAN}

Penyuluhan kesehatan mengenai ASI Ekslusif dilakukan kepada 25 responden ibu hamil yang berkunjung ke Puskesmas Pondok Cabe Ilir. Kegiatan dilaksanakan pada tanggal 30 September 2019. Meteri yang diberikan terkait ASI Ekslusif antara lain mengenai (1) Pengertian ASI Ekslusif: ASI eksklusif adalah pemberian ASI (air susu ibu) sedini mungkin setelah persalinan, diberikan tanpa jadwal dan tidak diberi makanan lain, walaupun hanya air putih,sampai bayi berumur 6 bulan (kecuali obat dan vitamin).

Setelah 6 bulan, bayi mulai dikenalkan dengan makanan lain dan tetap diberi ASI sampai bayi berumur dua tahun, (2) pentingnya ASI Ekslusif: Mempunyai zat-zat gizi yang lengkap, Mudah dicerna dan diserap, Melindungi terhadap infeksi Tanpa biaya, (3) manfaat ASI Ekslusif, (4) kelebihan ASI dibandingkan dengan susu formula, (5) posisi menyusui yang benar dan (6) waktu pemberian ASI: Diberikan kapanpun Bayi mau. Pelatihan dilakukan dengan menggunakan media phantom dan power point (Gambar 1).

Pada pelatihan perawatan payudara media yang digunakan adalah phantom. Materi yang diberikan terkait perawatan payudara yaitu, (1) tujuan Perawatan Payudara, (2) langkah-langkah Perawatan Payudara (Breast Care) selama kehamilan, (3) senam Teratur, (4) Memakai Bra yang pas. Sebelum dan setelah melakukan penyuluhan dan pelatihan dilakukan pengisian kuesioner untuk emlihat sejauh mana pengetahuan ibu sebelum dan sesudah dilakukan penyuluhan Kesehatan.

Terdapat beberapa tujuan perawatan payudara antara lain yaitu; memelihara kesehatan dan kebersihan payudara terutama puting susu, melenturkan dan menguatkan puting susu sehingga memudahkan bayi untuk menyusui, merangsang kelenjar-kelenjar air susu sehingga produksi ASI banyak dan lacar dapat mendeteksi kelainan-kelainan payudara secara dini dan melakukan upaya untuk mengatasinya, mempersiapkan mental (psikis) ibu untuk menyusui.

Langkah-langkah Perawatan Payudara (Breast Care) bisa dilakukan dengan beberapa tahapan. Pertama, setiap pagi dan sore sebelum mandi meneteskan minyak kelapa / baby oil pada sepotong kasa atau kapas, lalu mengusapkannya pada kedua puting susu. Lalu tunggulah kira-kira lima menit, kemudian gosok puting susu ibu dengan kain kasa/kapas sehingga semua kotoran 
terlepas. Ini berfungsi agar kotoran yang melekat pada puting susu dapat lepas dan jika nanti diisap bayi tidak lekas lecet.

Kedua, genggamlah tangan kanan ibu yang telah berminyak atau bersabun, tinju kanan (punggung jari-jari menghadap payudara) dan digosok pada buah dada dengan arah pangkal sampai ke ujung puting susu. Lakukanlah sehingga seluruh permukaan payudara ibu tergosok kira-kira 25 kali. Pekerjaan ini diulangi tetapi tidak memakai tinju melainkan dengan sisi telapak tangan, lakukan kira-kira 25 kali.

Ketiga, pelintirlah kedua puting susu ibu sambil ditarik ke depan, dengan demikian puting susu tetap akan menonjol keluar sehingga bayi ibu dapat mengisap puting susu dengan mudah.
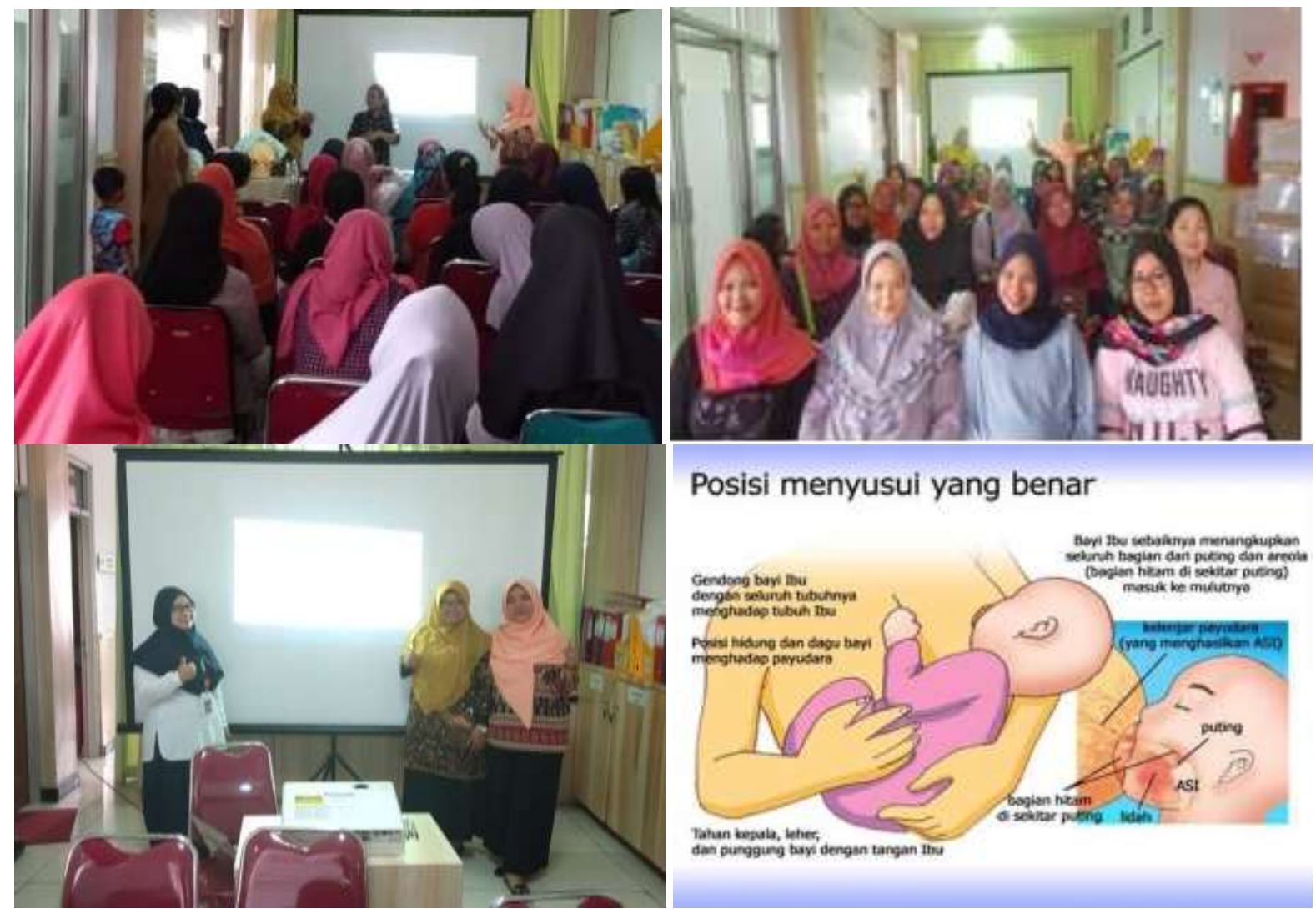

Gambar 1. Rangkaian Foto Pelatihan Perawatan Payudara (sumber : Data Primer dan google.com)

Untuk meningkatkan produksi ASI dengan baik, ibu juga perlu melakukan olahraga secara rutin. Selain itu olahraga juga bermanfaat untuk menghindari stress pada ibu hamil. Gerakan yang dapat dilakukan pada olahraga antara lain yaitu posisi berdiri, tangan kanan memegang bagian lengan bawah kiri dekat siku, sebaliknya tangan kiri memegang lengan bawah kanan (seperti orang bersidekap). Kemudian tekan kuat- kuat ke arah dada dengan cara mempererat pegangan, sehingga terasa tarikannya pada otot-otot di dasar payudara. Selanjutnya lemaskan kembali. Lakukan berulang-ulang hingga 30 kali.

Pegang bahu dengan kedua ujung tangan, kemudian siku diputar ke depan sehingga lengan bagian dalam mengurut (massage) payudara ke arah atas. Diteruskan gerakan tangan ke atas ke belakang dan kembali pada posisi semula. Lakukan latihan ini 20 kali putaran. 

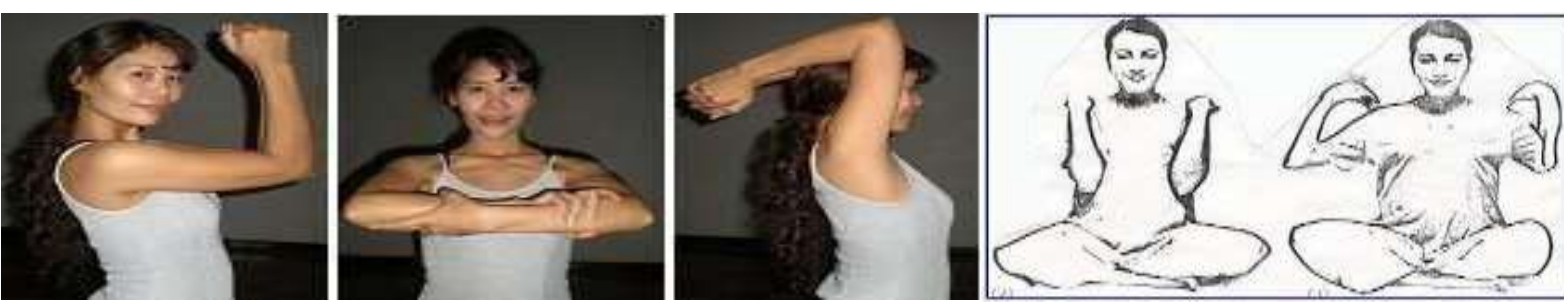

Gambar 2. Senam Payudara (sumber : google.com)

Banyak media promosi kesehatan yang dapat digunakan dalam memberikan edukasi ibu terkait ASI Ekslusif. Pilihan media seperti phantom merupakan salah satu alternative yang bagus dikarenakan media tersebut dapat digunakan sebagai alat peraga. Media promosi kesehatan yang baik adalah media yang mampu memberikan informASI atau pesan-pesan kesehatan yang sesuai dengan tingkat penerimaan sasaran, sehingga sasaran mau dan mampu untuk mengubah perilaku sesuai dengan pesan yang disampaikan (Susilowati, 2016).

Perlu dilakukan upaya yang signifikan untuk mengatASI masalah gizi pada balita salah satunya dengan pemberian ASI ekslisif pada bayi. ASI Ekslusif yaitu pemberian ASI saja pada bayi sejak lahir tanpa ada tambahan makanan yang lain termasuk air putih, kecuali vitamin dan obat (Kemenkes, 2017). Prevalensi ASI Ekslusif yang rendah dipengaruhi oleh banyak faktor antara lain pengetahuan ibu yang kurang akan pentingnya ASI Ekslusif serta bendungan ASI yang terjadi pada saat masa nifas yang dikarenakan kurangnya pengetahuan dan keterampilan ibu dalam melakukan perawatan payudara.

Perawatan payudara selama kehamilan adalah salah satu bagian penting yang harus diperhatikan sebagai persiapan dalam pemberian air susu ibu (ASI). Banyak ibu yang mengeluh bayinya tidak mau menyusu, biasanya ini disebabkan oleh faktor teknis seperti puting susu yang masuk atau posisi menyusui yang salah. Dalam meningkatkan pemberian ASI pada bayi, ibu-ibu membutuhkan bantuan dan informASI serta dukungan agar merawat payudara pada saat hamil untuk mempersiapkan ASI pada saat melahirkan sehingga menambah keyakinan bahwa mereka dapat menyusui bayinya dengan baik dan mengetahui manfaat perawatan payudara pada saat hamil (Fitriani, 2013).

Perawatan payudara juga dapat dilanjutkan pada masa nifas, penelitian yang dilakukan oleh Elvira dan Panjaitan (2017) menunjukkan adanya hubungan antara pengetahuan ibu nifas dengan sikap dalam melakukan perawatan payudara di Rumah Sakit Kartika Husada. Perawatan payudara pada masa nifas dapat mengurangi ibu dari kejadian payudara bengkak dan mastitis. Perawatan ini juga bertujuan untuk mencegah tersumbatnya saluran susu sehingga memperlancar pengeluaran ASI (Saleha, 2009).

Ibu Hamil yang semasa menyusui tidak melakukan perawatan payudara produksi ASInya tidak lancer (Alhadar dan Umaternate, 2917). Selain itu penurunan produksi ASI setelah melairkan dapat disebabkan oleh cara menyusui yang kurang baik (Pratiwi, 2012). Perawatan payudara yang baik dan edukasi kepada ibu hamil mengenai ASI Ekslusif dapat membantu ibu memberikan ASI dengan baik sehingga produksi ASI lancar

\section{KESIMPULAN}

Perlu dilakukan pelatihan dan edukasi terkait perawatan payudara dan ASI Ekslusif pada ibu hamil. Pelatihan dengan media phantom merupakan pilihan media yang tepat dalam memberikan edukasi kepada ibu hamil terkait perawatan payudara serta ASI Ekslusif. Diperlukan upaya edukasi yang baik dengan media yang tepat kepada ibu hamil dan dilakukan secara terus menerus. 


\section{UCAPAN TERIMA KASIH}

Kami mengucapkan terima kasih kepada Pemerintah Kabupaten Tangerang Selatan dan Puskesmas Pondok Cabe Ilir, yang telah berkonstribusi dalam mendukung pengabdian masyarakat ini.

\section{DAFTAR PUSTAKA}

Alam, S. and Syahrir, S. (2016) 'Faktor - Faktor Yang Berhubungan Dengan Teknik', Public Health Science Journal Volume 8, Nomer.

Alhadar, F dan Umaternate, I. (2017). Pengaruh Perawatan Payudara Pada Ibu Hamil Terhadap Peningkatan Produksi ASI di Wilayah Kerja Puskesmas Kota Kecamatan Kota Ternate Tengah Tahun 2016. Jurnal Riset Kesehatan, 6 (1), 2017, 7-12.

Elvira, D dan Panjaitan, AA. (2017). Hubungan Antara Pengetahuan Ibu Nifas Dnegan Sikap dalam Melakukan Perawatan Payudara di Rumah Sakit Kartika Husada Kabupaten Kubu Raya Tahun 2017. Jurnal Kebidanan, Volume 7 Nomor 1 mei 2017.

Fahriani, R., Rohsiswatmo, R. and Hendarto, A. (2014) 'Faktor yang Memengaruhi Pemberian ASI Eksklusif pada Bayi Cukup Bulan yang Dilakukan InisiASI Menyusu Dini (IMD)', Sari Pediatri, Vol. 15, No. 6 April 2104.

Farrer, H. (2001) Perawatan maternitas. Jakarta: EGC.

Fitriani, F. (2013) Gambaran Pengetahuan Ibu Hamil Tentang Perawatan Payudara Selama Kehamilan dan Pada Masa Nifas Di RB Mattiro Baji Gowa Tahun 2013. Skripsi. Universitas Islam Negeri Alauddin Makassar.

Jafar, N. (Year) ASI Eksklusif. Scientific Seminar Studies Program Faculty of Public Health Nutrition Makassar, 2011.

Kemenkes (2015) Kesehatan dalam Kerangka Sustainable Development Goals (SDGs). Ditjen Bina Gizi KIA: Kemenkes RI.

Kemenkes (2017) Profil Kesehatan Indonesia. Kemenkes RI.

Kemenkes (2018) Riset Kesehatan Dasar (Riskesdas). Kemenkes RI.

Meihartati, T. (2017) 'Hubungan antara perawatan payudara dengan kejadian bendungan ASI', Jurnal Kebidanan dan Keperawatan, Vol. 13, N, pp. 19-24.

Pusdatin. (2018). Data dan InformASI Profil Kesehatan Indonesia. Kemenkes

Pengan, J. et al. (2015) 'Hubungan antara Riwayat Pemberian ASI Ekslusif dengan Kejadian Stunting pada Anak Usia 12-36 Bulan di Wilayah Kerja Puskesmas Luwuk Kecamatan Luwuk Selatan Kabupaten Banggai Sulawesi. Skripsi

Pratiwi, P. (2012). Gambaran Faktor-Faktor Yang Mempengaruhi Pemberian ASI Ekslusif di kelurahan Kunciran Indah Tangerang. Skripsi.

Rustam, M. (2009) Sinopsis Obstetri Fisiologi dan Patologi edisi 2, Jakarta: EGC.

Saleha, (2009). Asuhan Kebidanan Pada Masa Nifas. Jakarta: Salemba Medika.

Susilowati, D. (2016). Promosi Kesehatan. Kemenkes RI

Trisnawati, E dan Distrilia, A. (2018). Perawatam Payudara Sebagai Treatment Kelancaran ASI. Buletin Al Ribaath, Vol.15, No. 2, Desember 2018. 